\title{
Optogenetics in Brain Research: From a Strategy to Investigate Physiological Function to a Therapeutic Tool
}

\author{
Elena Montagni ${ }^{1}\left(\mathbb{D}\right.$, Francesco Resta $^{1}$, Anna Letizia Allegra Mascaro ${ }^{1,2} \mathbb{D}$ and \\ Francesco Saverio Pavone 1,3,4,* \\ 1 European Laboratory for Non-Linear Spectroscopy, University of Florence, 50019 Sesto Fiorentino, Italy \\ 2 Neuroscience Institute, National Research Council, 56121 Pisa, Italy \\ 3 National Institute of Optics, National Research Council, 50125 Firenze, Italy \\ 4 Department of Physics and Astronomy, University of Florence, 50019 Sesto Fiorentino, Italy \\ * Correspondence: pavone@lens.unifi.it
}

Received: 3 June 2019; Accepted: 25 July 2019; Published: 20 August 2019

check for updates

\begin{abstract}
Dissecting the functional roles of neuronal circuits and their interaction is a crucial step in basic neuroscience and in all the biomedical field. Optogenetics is well-suited to this purpose since it allows us to study the functionality of neuronal networks on multiple scales in living organisms. This tool was recently used in a plethora of studies to investigate physiological neuronal circuit function in addition to dysfunctional or pathological conditions. Moreover, optogenetics is emerging as a crucial technique to develop new rehabilitative and therapeutic strategies for many neurodegenerative diseases in pre-clinical models. In this review, we discuss recent applications of optogenetics, starting from fundamental research to pre-clinical applications. Firstly, we described the fundamental components of optogenetics, from light-activated proteins to light delivery systems. Secondly, we showed its applications to study neuronal circuits in physiological or pathological conditions at the cortical and subcortical level, in vivo. Furthermore, the interesting findings achieved using optogenetics as a therapeutic and rehabilitative tool highlighted the potential of this technique for understanding and treating neurological diseases in pre-clinical models. Finally, we showed encouraging results recently obtained by applying optogenetics in human neuronal cells in-vitro.
\end{abstract}

Keywords: light-delivery systems; in vivo; channelrhodopsin; rehabilitation; stimulation; neurons; neurodegenerative disease

\section{Introduction}

Optogenetics is a non-invasive technique largely used in neuroscience to study brain circuit functions on multiple scales by allowing neuronal activity manipulation with high temporal and spatial resolution. Thanks to its versatility, optogenetics is progressively becoming the gold standard for circuit manipulation [1,2]. The high spatial resolution of this technique makes it one of the most precise low-invasive brain stimulation strategy, highly suitable for the development of targeted therapeutic protocols for neurodegenerative diseases and injuries, such as Parkinson, depression, stroke, and multiple sclerosis [3,4]. Indeed, although optogenetic treatments are still limited to pre-clinical models, they are proving to be a promising strategy. Therefore, in this review, we firstly described the basic components of the optogenetics technique, i.e., light-activated proteins and light delivery systems. Secondly, we reported recent applications to cortical and subcortical neuronal circuits in vivo, which allowed us to identify physiological mechanisms and new plausible targets for light-based therapies. Then, we moved on dysfunctional networks, where different optogenetic approaches have allowed, 
(i) to trigger, (ii) to modify, or (iii) to mimic pathological behaviors, leading the way to feature innovative therapeutic interventions. Finally, we introduced recent studies that exploited optogenetics as a rehabilitation strategy, showing the potential of this technique to replace drug treatments in pre-clinical models.

\subsection{Opsins: An Optical Tool to Manipulate In-Vivo Neural Networks}

Optogenetics exploits genetically encoded proteins called opsins to control the activity of targeted cell populations with light [5]. Opsins are a wide group of light-activated transmembrane proteins. These light-gated proteins can be categorized according to biophysical properties in ion channels, pumps, and G-protein coupled receptors, and in type I or type II depending on their microbial or animal derivation respectively [6]. In the last years, the bioengineering of optogenetic actuators has focused on improving existing opsin in terms of activation and deactivation kinetics leading to faster, slower, or step function opsins that best meet the increasing experimental requirements. Furthermore, different colour-tuned chimeras have been generated allowing multimodal manipulation of the same neuronal circuit simply by adjusting the light wavelength applied $[7,8]$. The most common opsin used to excite neurons is the blue light-activated cation channel, Channelrhodopsins 2 (ChR2) [9], while the anion-conducting proteins named halorhodopsin from Natronomonas pharaonis (NpHR) is widely used to silence excitable cells when illuminated with yellow light [10].

Optogenetic actuators must be conveyed and expressed in specific neuronal populations. Currently, there are two main strategies for targeting opsins-Virus-based transfection methods [11,12] or transgenic animal lines. Although virus-based transfection methods are limited by the variability in transduction efficiency, this technique is widely used to lead a local transfection in brain regions of interest with two main advantages: (i) The number of transfected neurons can be adjusted according to the volume of virus injected into the tissue and (ii) the afferent or efferent projections from a region can be selectively transfected and stimulated avoiding unwanted excitation of collateral targets [13,14]. Conversely, transgenic animal lines do not suffer from opsins distribution variability and allow homogeneous protein expression in wide regions of the nervous system [15-17]. However, the long-term expression of hexogen proteins in transgenic mice could induce possible toxic effects, such as abnormal axonal morphology or aberrant electrical activity as shown respectively for opsins or calcium sensor expression $[18,19]$. The development of the transgenic mice line is strictly dependent on the number of available genetic promoters used to drive the process, which is still limited. This problem is partially overcome thanks to advanced genetic manipulations that exploit the Cre recombinase system for controlling gene expression [20]. All these fine and flexible applications make optogenetics a non-invasive innovative strategy.

\subsection{Light Sources and Light Delivery Systems}

To investigate the causal relationships between targeted neuron modulation and related-behavioural outcomes, a high temporal precision is required. In addition, since the architecture of brain circuits is developed on different spatial scales, from a microscopic to macroscopic level [21-25], manipulating techniques shall ideally be able to span several spatial resolutions. In this section, we will describe the approaches of light sources and light delivery systems recently developed to address different spatio-temporal scales.

One-photon (1P) wide-field illumination is the first and most common method to perform optogenetic stimulation using visible light. Historically, it was possible to drive optogenetic stimulation of opsin expressing neurons in a large field of view (FOV) using an epifluorescent lamp or a light-emitting diode (LED) as a light source [26]. An advantage of $1 \mathrm{P}$ illumination is the low-power density required to achieve the minimum level of irradiance to generate action potentials [26-28]. At the same time, the low spatial resolution of $1 \mathrm{P}$ wide-field illumination does not reach single-cell optogenetic excitation. To increase the spatial resolution the light source can be changed, for example by replacing the LED with micro-LED ( $\mu$ LED) or laser, which allow to selectively excite a significantly reduced region of 
interest using light in the visible spectrum [29-33]. Although 1P wide-field illumination cannot reach a single-cell resolution and lacks the spatial confinement of illumination, this technique is an important resource for mesoscale mapping the functional networks at the level cortex (Figure 1C) [34,35].

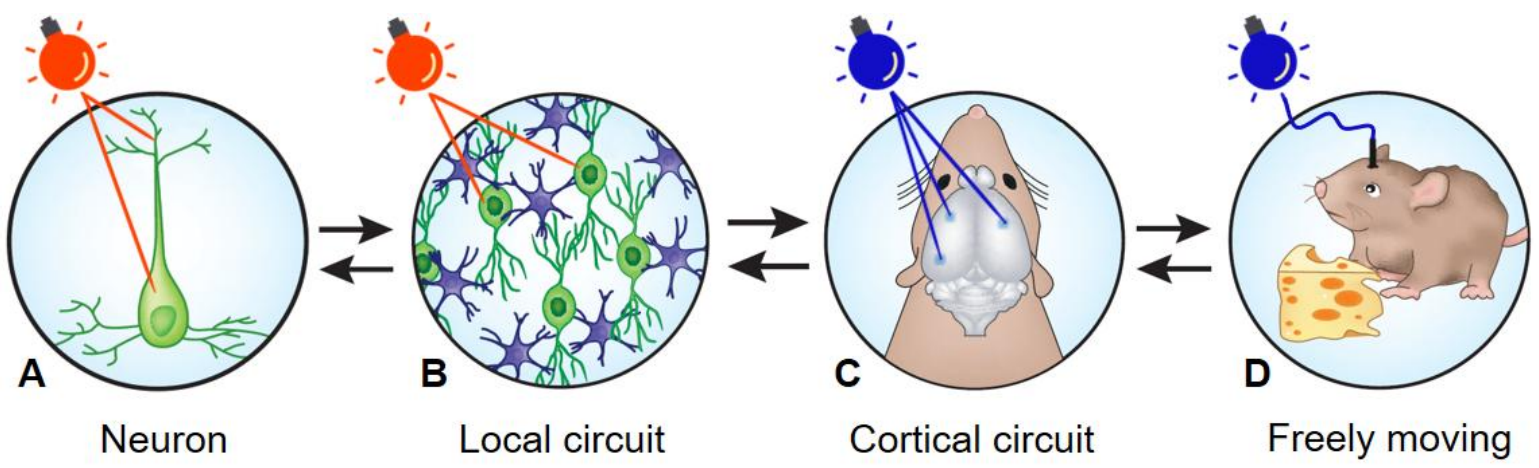

Figure 1. Optogenetic manipulation with different spatial resolutions. (A) Representative image of two-photon (2P) excitation method, which provides temporally precise control of neuronal firing. The high spatial resolution of the technique allows for the stimulating of targeted compartments of individual neurons at the dendritic, somatic, and axonal level. The two-photon beam can be split to irradiate multiple spots in the imaging plane using different approaches, such as spatial light modulators (SLMs) or holographic projection (HP). (B) Spatially patterned excitation sequences can be reproduced to map and modulate the connectivity of individual neurons within local circuits. (C) A representative example of one-photon patterned illumination. This technique enables us to trigger extensive cortical network dynamics and mimic natural activity patterns for the investigation of interand intra-cortical interactions. (D) Deep brain stimulation using optical fibres provides a method to probe the causal relationships between the activity of neuronal ensembles and behaviour in the most natural conditions allowed. Adapted by permission from Springer Nature [17].

Alternatively, two-photon (2P) stimulation is a widely used technique to reach single-cell modulation. Indeed, scattering properties of biological tissues prevent the deep penetration of light, unless transparent animals are used (e.g., zebrafish) [36-38]. Two-photon (2P) stimulation uses the simultaneous absorption of two near-infrared photons $(1064 \mathrm{~nm})$ to excite target proteins. Consequently, this technique allows for stimulating deeper in the biological tissue with the additional advantage of the single-cell resolution.

The conventional 2P microscope (scanning based on galvanometer mirrors $[39,40]$ ), is characterized by a micrometre-sized excitation volume. Therefore, high concentrations of opsin are required in the targeted cell to exceed the action potential threshold and allow us to optogenetically-evoke spikes in the neuron. Alternatively, other solution can be used: (i) High irradiation density, increasing the risk of tissue photodamage; (ii) opsins with slower-off channel kinetics for temporal integration, such as C1V1 or ReaChR2; or (iii) soma-targeted opsins, taking into account channel saturation properties [41-45].

One focal point is creating spatial excitation sequences to both investigate the basic connectivity within a circuit and interfere with them (Figure 1A,B). Different approaches are applicable depending on the complexity of the excitation patterns desired. The most adaptable and low-cost method is to move the plane in which the animal is positioned, but this solution does not allow a fast change of the excitation point [46]. Instead, surface light delivery systems, such as acoustic-optic deflectors (AOD) or galvanometer mirrors, allow a fast point by point spatial control of the laser beam to sequentially excite a different region of interest (ROI) in the FOV [28,43,47-50].

Moreover, spatial light modulators (SLMs) or holographic projection (HP) have the additional advantage to split the laser beam in multiple focal spots allowing simultaneous stimulation of different ROI in a single FOV [27,51-53]. By combining holography techniques and galvanometers mirrors, it is possible to achieve three dimensional (3D) holographic stimulation to excite target cells at different depths simultaneously $[51,54,55]$. 
Limitations of digital holographic techniques are due to the inhomogeneous light distribution during stimulation execution and to the low axial resolution. The latter leads to an aspecific excitation of several cell layers in the biological tissue. Then, to overcome this issue it is possible to use temporal focusing (TF), which eliminates the trade-off between the target size in the lateral $(\mathrm{x}, \mathrm{y})$ and axial $(\mathrm{z})$ plane. Thus, large areas within the FOV are illuminated maintaining good spatial confinement [27,56-58].

Regardless of the method used to drive optogenetic excitation, both $1 \mathrm{P}$ and $2 \mathrm{P}$ configurations suffer from light scattering that limits the depth achievable to under a few microns $(<1 \mathrm{~mm})$ from the cortical surface in living animals. To address excitation in subcortical regions optical fibres are necessary. Although the implant of an optical fibre is an invasive process which could cause mechanical damages to the brain tissue, this technique enables a reproducible and longitudinal photostimulation of neuronal activity in the deep brain region (Figure 1D).

Fibres have the additional advantage of being implantable in freely moving animals, thus allowing us to study how targeted perturbation can interfere with physiological behaviours or improve pathological conditions in high-throughput behavioural experiments with chronic implants. This system has the advantage of reducing tissue damage from repeated fibre insertions, as well as the risk of infection when long-term in-vivo studies are performed [59,60]. The standard fibre optics are flat-face fibres (FFs), which deliver light only in a small and fixed tissue volume located on the tip of the fibre [61]. Recently, tapered optical fibres (TFs) enable excitation along a larger volume thanks to an homogeneous cylinder of light along the entire tapered fibre. Moreover, in the TFs the light input angle can be adjusted to select the light-emitting portion, this characteristic allows us to illuminate two different regions of the brain simultaneously along the same fibre [62-64]. Furthermore, optic fibres can be coupled to recording electrodes (optrodes) for simultaneous electrophysiological recording and photostimulation [59], thus taking advantages of both electrophysiology and optogenetic in the same device. Furthermore, to increase the complexity of behavioural paradigms that can be investigated, innovative implantable wireless optogenetic devices are being developed [65-70].

Regardless of the technique used to deliver the light, the tissue heating due to sustained illumination requires an accurate consideration. Indeed, many physiological processes are temperature-sensitive and specific cell types in different brain regions (such as the striatum) can suppress their firing rates when subjected to continuous illumination (10-15 $\mathrm{mW}$ ) even in the absence of opsin expression [71]. Although the time constant for the heating of neuronal tissue with light is slower than the time necessary for opsins to alter the neuronal activity, accurate illumination strategies are highly recommended to reduce thermally induced side effects. Therefore, the correct choice of the numerical aperture, the core diameter. and the wavelength is necessary to minimize heating effects with optical fibres. Moreover, the stimulus frequency and pulse length are also important to reduce the risk of phototoxicity and heat damage in the living tissue [33,71-73].

\section{Towards a Deeper Understanding of Brain Circuits Functions, Using Optogenetics}

Neuronal networks in living organisms are highly interconnected. In vivo, the use of optogenetics allows the association of a selective, specific, and finely controlled stimulus with an output readout such as a behavioural reaction $[24,74,75]$ or a neuronal response if combined with electrophysiology techniques or optical indicators [76-79]. This permits us to study the functional connectivity on multiple scales from a single neuron to the whole brain in physiological or pathological conditions [80-82]. Here we review several optogenetic approaches that allowed us to dissect and identify new functional roles of neuronal circuits highly involved in neurological diseases treated later in this review, since these studies help to identify more target (light-based) therapies. In particular, we focus on recent discoveries at the cerebral cortex and basal ganglia level. Basal ganglia (BG) take part in different processes such as motor control, executive functions, and emotion [83]. More in detail, motor circuit modulation is thought to be based on an activity balance between the direct and indirect pathway starting from the striatum, which regulates basal ganglia output to the thalamus (Figure 2A). The highly selective optogenetic control offered a unique opportunity to thoroughly understand the physiological 
functionality of the two pathways and how it is disrupted in Parkinson's disease. Indeed, the direct pathway activation using an excitatory opsin (ChR2 [84]) led to a movement increase, while indirect pathway activation suppressed the motor program [85] (Figure 2B).

\section{A MOTOR CIRCUIT MODULATION}

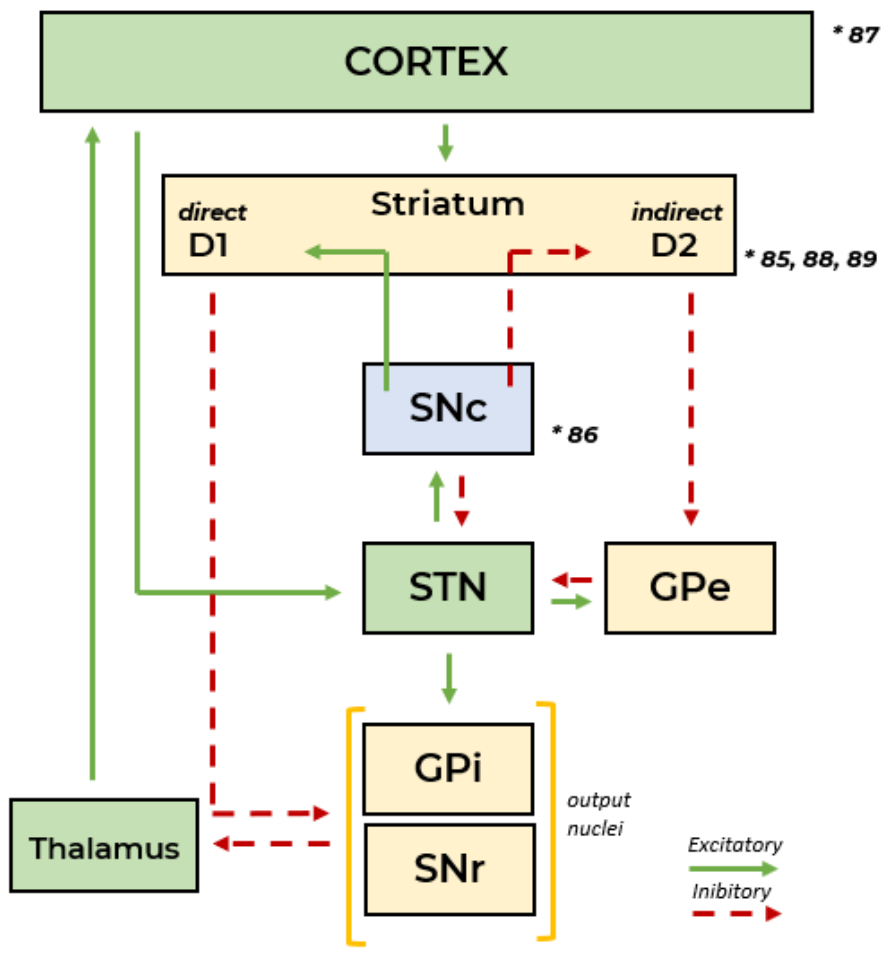

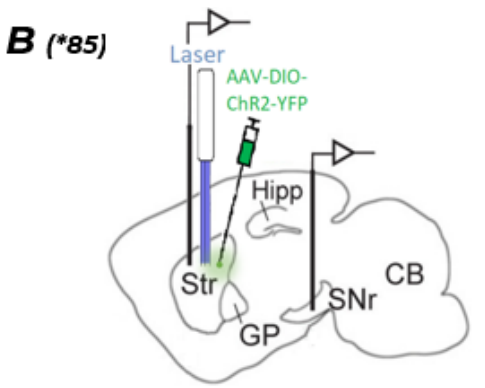

$C_{(" 86)}$

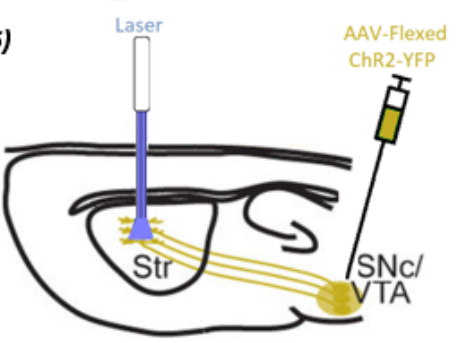

D (*87)

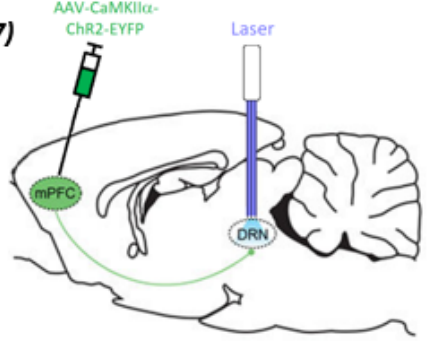

Figure 2. Optogenetic application to study the cortical-basal ganglia-thalamocortical circuit involved in motor control. (A) Connectivity diagram showing excitatory and inhibitory pathways. Abbreviations: D1 and D2, dopamine receptor subtypes. SNc, substantia nigra pars compacta. STN, subthalamic nucleus. GPe, external glob pallidus. GPi, internal globus pallidus. SNr, substantia nigra pars reticulata. Works where viral transfection involved a specific nucleus are signed with an asterisk on the right. (B) Representative scheme showing the placement of bilateral optical fibres (blue) in dorsomedial striatum (Str) with unilateral recording array in either striatum or $\mathrm{SNr}$ (black). Virus injection was performed bilaterally into dorsomedial striatum (green). Adapted from [85]. (C) Representative methodological scheme of the activation of $\mathrm{SNr}$ axon terminals in the thalamus-Optical fibre (blue) was in dorsal striatum to stimulate projecting dopamine axons from SNc. Virus (yellow) was injected at ventral tegmental areas (VTA) or SNc. Adapted by permission from Springer Nature [86]. (D) Representative scheme of activation of $\mathrm{mPFC}$ axon terminals in the DNR using optical fibre (blue). Virus (green) was injected in $\mathrm{mPFC}$. Adapted from [87] with permission from Elsevier.

Moreover, the direct and indirect pathways are involved in the process of action sequences learning. Little is known about how action sequences are organized. They could be organized as response chains activated in series by sensory feedbacks or hierarchical sequences with multiple levels of control. To address this issue, Geddes et al. in 2018 [88] selectively perturbed the two pathways by expressing hChR2(H134R) in the striatal MSNs [8]. By using a state-dependent closed-loop optogenetic stimulation and interference they demonstrated that action sequences in a complex task are controlled independently, suggesting a hierarchal organization-striatal direct pathway facilitates actions and controls sequence start/stop, while indirect pathway inhibits actions and mediates the switch to the following sequence. These results provide important information in order to elucidate how 
cortico-basal ganglia circuits work in coordination processes [88] and suggest new targets for the treatment of Parkinson's disease in which the action sequences organization is highly compromised.

A similar optogenetic approach was used by Wang et al. in 2018 [89] to dissect the role of the direct and indirect pathways in controlling the cognitive flexibility, an essential executive function that enables individuals to cope with changing environments by switching between strategies. Indeed, cognitive flexibility deficits are involved in disorders, such as Parkinson's and schizophrenia. The possibility to bidirectionally stimulate the two different population of striatal MSNs by expressing ChR2 or NpHR permitted the authors to identify an opposite action of these two pathways in cognitive regulation in freely moving mice: Disrupting (direct) and facilitating (indirect) the performance without affecting the acquisition or retention of discrimination learning.

In recent years the development of genetically encoded activity sensors allowed monitoring hundreds of individual neurons simultaneously using calcium or voltage indicators imaging. Combining photostimulation with neuronal imaging allowed us to achieve an 'all-optical system' for long-term low-invasive studies of manipulated neuronal patterns [90-93]. Critical points in the all-optical approaches are principally due to the spectra overlap between optogenetic actuators and neuronal sensors, and to the photoswitching properties of some proteins in response to different wavelengths $[77,94]$.

This combination of techniques has been used from Howe et al., where the calcium indicator GCaMP6f was expressed into the ventral striatum dopamine neurons to test the hypothesis that specific striatal dopamine signalling patterns modulated locomotion movements, an important target in Parkinson's treatments. By transfecting the same neurons with ChR2, it has been possible to replace the phasic dopamine axon signalling observed during physiological locomotion or spontaneous initiations (Figure 2C). Thus, the authors showed that optogenetic stimulation of dorsal-striatum-projecting dopamine axons could rapidly trigger locomotion bouts and shift rhythmic acceleration, demonstrating the importance of dorsal striatal activities on locomotion movements [86].

However, one limitation of optogenetics as a stimulation technique is the undesired excitation of collateral targets due to the projections to multiple neurons expressing optogenetic-actuators. To overcome the problem, it is possible to anatomically select only the transfected axonal projections connected with brain regions of interest. This approach has been adopted by Warden et al. [87] to study the role of the Medial Prefrontal Cortex (mPFC) in goal-oriented behaviour that is impaired in pathological states such as depression. More in detail, to mimic the mPFC control on Dorsal Raphe Nucleus (DNR), a virus-containing ChR2 was injected into the $\mathrm{mPFC}$ and its axonal projections to DNR have been selectively excited with optical fibre implanted in the DNR (Figure 2D). In this study, a clear, rapid, and reversible effect on active behaviour selection has been observed after optogenetic stimulation (immobility average was $97 \%$ in the pre-protocol epoch compared to an immobility average of $39 \%$ during the protocol epoch). Thus, demonstrating the importance of mPFC in the generation of behavioural responses to challenging situations [87].

\section{Optogenetics to Dissect Disease Neural Circuitry}

Optogenetics is strongly used to study dysfunctional mechanisms underlying neurological disease and injuries, with different approaches. First, it can be used to study functional connectivity in abnormal conditions. For this purpose, all-optical approaches allowed to real-time SEanalyze the altered connectivity and the following circuit reorganization over the weeks. Thus, thanks to the mesoscale optogenetic mapping of ChR2-evoked voltage-sensitive dye (VSD) responses, Lim et al. were able to study how the neuronal connectivity changes across both cortical hemispheres after a targeted cortical stroke. They showed an heterogeneous recovery in the damaged areas, associated with changes in functional connectivity even in the non-injured hemisphere (Figure 3A) $[46,95,96]$. Another example was Xie et al. in 2013, who used optogenetic stimulation combined with electroencephalography and electromyography recording to perform a non-invasive investigation of the acute effect of global 
ischemia on sensory and motor outcome with high temporal resolution. The authors showed an incomplete recovery of the sensory processing, while motor output was nearly fully recovered [97].
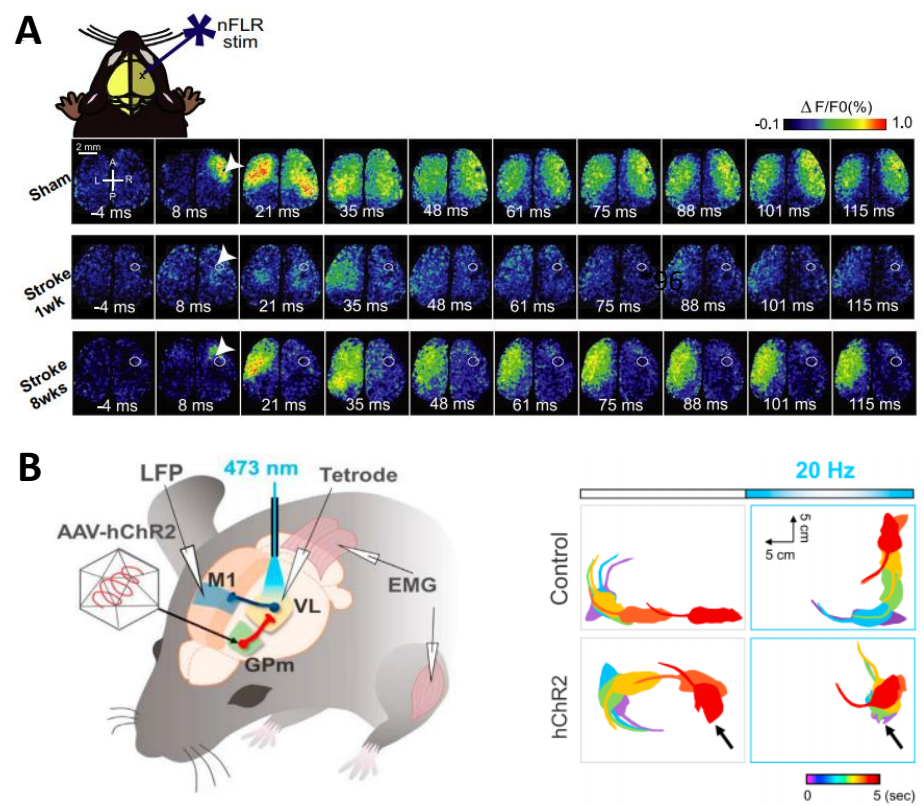

Figure 3. Brain circuit functions in pathological conditions. (A) Example of quantitative voltage-sensitive dye (VSD) responses in a bilateral craniotomy preparation after photostimulation of the right (injured) forelimb somatosensory cortex in a sham animal (top), 1 week after stroke (middle), and 8 weeks after stroke animal (bottom). The white circle indicates the lesion in the stroke animals. White arrows indicate laser photostimulation target. Adapted from [46]. (B) Left: Lepresentative scheme for photostimulation of GPm-VL synapses and recording activities from VL neurons and body muscles. Right: Representative time series of video frames $5 \mathrm{~s}$ before (white rectangle) and during (blue rectangle) photostimulation of the GPm-VL. Adapted from [98] with permission from Elsevier.

In the study of diseased neural circuitry, optogenetics has also been used as a tool to modify the activity of targeted neuronal populations in pathological conditions, in order to assess their potential implications. This mechanism has been applied to study dysfunctional neurological patterns characteristic of obsessive-compulsive disorders (OCDs) associated with repetitive behaviours. In detail, abnormalities in the cortico-basal ganglia circuit, related to the lateral orbitofrontal cortex (1OFC) are implicated in these disorders. Indeed, MSNs in pathological animals show a higher baseline firing compared to healthy mice. Optogenetic stimulation of targeted axonal projection from 1OFC to striatum led to an inhibition of MSNs spiking and a reduction in the obsessive-compulsive behaviour, confirming a key role of the 1OFC-striatal pathway in these disorders [99].

Another approach was to use optogenetics as a triggering factor to evoke and mimic pathological behaviours. For example, a kindling-induced variant of the classical model of epilepsy has been developed to study epileptogenesis processes modulating the severity and the duration of seizures by applying ChR2 stimulation into the primary motor cortex (M1) [100]. Another case where optogenetics was used to trigger pathological behaviour regards dopamine neurons in the ventral tegmental area (VTA), which have a crucial role in the stress response. These neurons have two different patterns of firing: Low-frequency tonic and high-frequency phasic firing. Optogenetic phasic stimulation managed to discriminate circuits involved in the depression and social-defeat stress-optogenetic inhibition of the VTA-NAc projection induced resilience, while inhibition of the VTA-mPFC projection promoted stress susceptibility [101]. Using the same principle, optogenetics enabled the identification of pathological patterns underlying Parkinson's disease (PD), a neurodegenerative disease characterized by several motor deficits. The hallmark of PD is the loss of SNc dopaminergic neurons innervating the 
striatum, which leads to basal ganglia circuitry dysfunction. Nevertheless, the regulation effects of BG projections in this condition was unknown. Optogenetic modulation allowed the ability to show that inhibitory medial globous pallidum (GPm) input to ventrolateral thalamic neurons (VL) was critical for the suppression of locomotion. Indeed, inhibitory synaptic input from GPm was able to induce an excitatory motor signal in thalamic neurons. This condition suggested a re-evaluation of the role of the two principal BG outputs (GPm and SNr) which could also lead to future innovative therapeutic interventions to improve debilitating conditions caused by dopamine deficiency. Furthermore, the frequency and light pulse width of GPm photostimulation evoked different muscle contractions: From basic muscle twitches by $1 \mathrm{~Hz}$ photostimulation, to a state of continuous muscle contraction when the high-frequency of GPm oscillations observed in PD was emulated (Figure 3B) [98]. This study introduces another feature of optogenetics-different stimulation modalities in the same context lead to opposite results. As discussed in the section on rehabilitation strategies, this condition should not be underestimated especially when optogenetics is applied as a therapeutic treatment.

\section{Light as Rehabilitative Strategy in Pre-Clinical Models}

In the following section, we will introduce recent studies that exploited optogenetics as a treatment and rehabilitation strategy compared to other low- or non-invasive brain stimulation techniques (NIBS). Indeed, NIBS like transcranial Electrical Stimulation (tES) or Transcranial Magnetic Stimulation (TMS) demonstrated promising results in post-stroke recovery, anxiety, and depression treatment, in addition to improving Parkinson's symptoms in human patients [102-109]. Nevertheless, these methods are non-selective and limited by the low spatial resolution, which induces activity changes of all cell types near the stimulated site. In contrast, optogenetics is selective for specific cell populations and it can bidirectionally modulate the brain activity with single-cell resolution and with a millisecond temporal precision [110]. Therefore, optogenetics is increasingly used as a rehabilitative and therapeutic tool for neurodegenerative disease and, although optogenetic treatments are still limited to pre-clinical models, this technique is proving to be a promising strategy.

\subsection{Parkinson's Disease}

Deep brain stimulation (DBS) is currently the most widely used neurostimulation system used for human therapy [111]. However, this strategy (i) requires surgery to implant an electrode in the brain, (ii) does not allow a selective neuronal excitation or inhibition, and (iii) the stimulus parameters are not suitable for a fine modulation of BG oscillations. Instead, the use of low-invasive techniques, like optogenetics, to lead direct-pathway activation allowed recovery of all motor deficits up to pre-lesion levels in a mouse model of PD, suggesting an highly selective therapeutic strategy for ameliorating Parkinsonian-debilitating conditions [80].

Since PD is related to an excitatory/inhibitory imbalance in the BG circuits [112], therapeutic optogenetic applications can target several neuronal populations at BG levels, from MSNs involved in direct and indirect pathways to glutamatergic neurons in the subthalamic nucleus (STN). Moreover, optogenetics offers a range of strategies that cover both excitation and inhibition modulation with high spatial resolution [113], as in the case of Yoon et al. that performed optical STN inhibition using halorhodopsin (NpHR). This condition led to an improvement in forelimb akinesia in a unilateral mouse model of PD [61] (the use of the contralateral forelimb was $9.8 \pm 6.3 \%$ in the control group vs $38.8 \pm 8.1 \%$ in NpHR group during stimulation), suggesting that the STN inactivation could reduce the firing pattern of output nuclei as GPi and SNr and leading an improvement in motor symptoms.

Optogenetic techniques were also used to specifically activate glutamatergic neurons in the ventroanterior motor thalamus. Seeger-Armbruster et al. identified a selective pattern of stimulation which led to rescue movement, in drug-induced Parkinsonian rats [114], highlighting the possibility to recreate physiological models of cellular activation is in order to achieve successful therapeutic strategies. Indeed, physiological patterns achieved using the timing of spikes from previously recorded single VA neurons and theta-burst patterns of stimulation (TBS) improved reaching in parkinsonian rats. 
The spatial precision of optogenetics can be increased by controlling the opsin gene expression by the Cre-recombinase system [20]. Thus, only neuron subpopulation projections connected to the target area are labelled and can be stimulated, ensuring no data influence by collateral projections stimulation. This was the case of Magno et al. where selective glutamatergic neurons in the secondary motor cortex (M2), innervating BG structure, were stimulated to control motor behaviour in the parkinsonian condition (Figure 4A). They showed that M2 photostimulation allowed the ability to improve motor functions leading to the recovery of the pathological inhibitory tone of the direct pathway $\left(61.7 \%\right.$ increase in average speed in $\mathrm{ChR}^{+}$lesioned animals compared to $\mathrm{ChR} 2^{-}$; these animals also didn't show a change in the Y-maze test suggesting that the stimulation did not affect nonmotor symptoms). Instead, the combination of optogenetics with pharmacological treatment (L-DOPA) led to an unexpected improvement in working memory performance (percentage of alternations in Y-maze test of $\mathrm{ChR2}^{+}$vs ChR2${ }^{-}$under L-DOPA treatment: $58.1 \pm 3.53$ vs. $41.3 \pm 3.66$ ) [115].
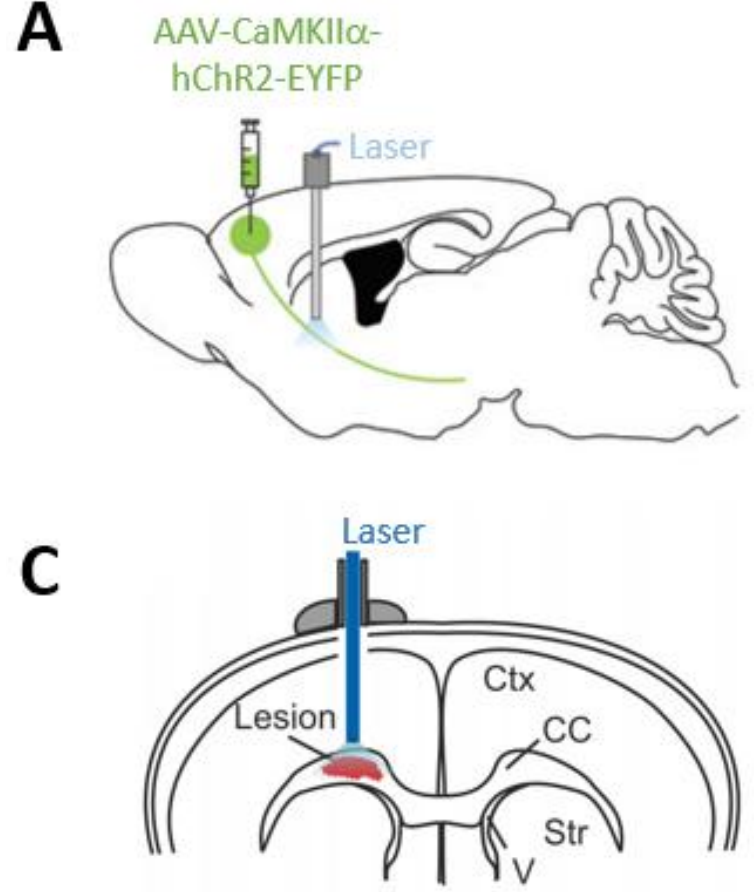

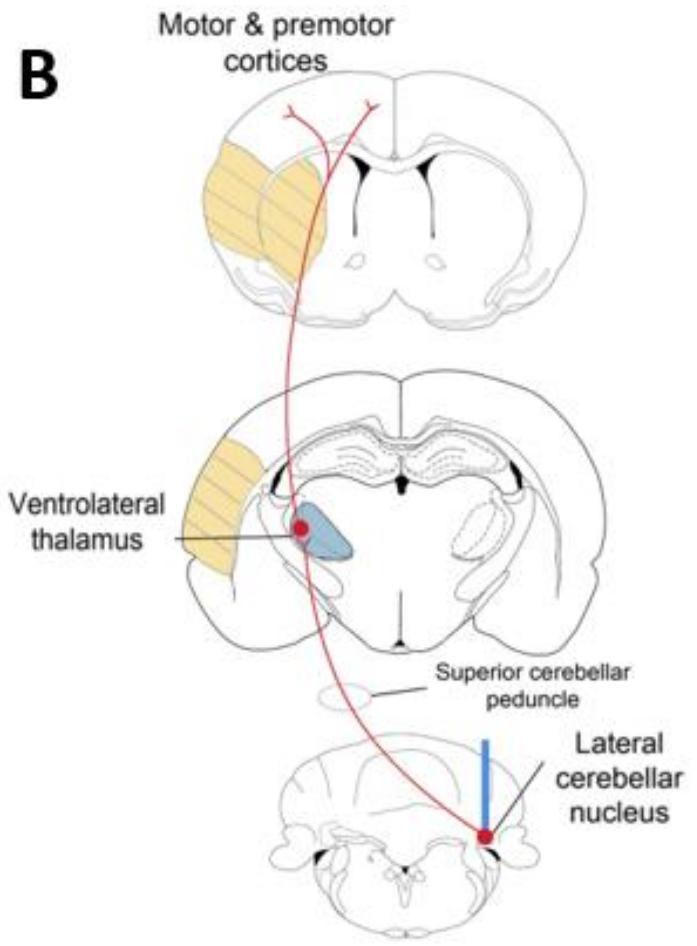

Figure 4. Representative schemes of optogenetic therapeutic pre-clinical application in Parkinson's, stroke, and multiple sclerosis. (A) Experimental scheme: ChR2 is expressed into the M2 area (green) and optical fibre (blue) is implanted over the dorsomedial striatum. Adapted from [115]. (B) Diagram showing the dentato-thalamo-cortical pathway stimulated (from the bottom to the top). Fibre cannula is implanted in the contralesional lateral cerebellar nucleus (LCN-bottom). The region of the yellow hatch marks represents the infarct areas (striatum and cortex). Adapted from [116]. (C) Scheme showing optogenetic neuronal stimulation of the lateral corpus callosum (CC). The optic fibre is placed above the demyelinated lesions (in red) to stimulate axonal projection of neocortex neurons. Abbreviations: Ctx, cortex; Str, striatum; V, ventricle. Adapted with permission of American Society for Clinical Investigation from [117].

Similar results have been obtained stimulating the primary motor cortex (M1) projections to STN. Once again, the stimulation frequency was also important: High-frequency optogenetic stimulation $(100 \mathrm{~Hz})$ ameliorated bradykinesia and increased movement speed (seconds in motion per trial increased from $48.6 \pm 4.3 \mathrm{~s}$ in unstimulated lesioned mice to $83 \pm 8.7 \mathrm{~s}$ ), while low-frequency stimulation $(30 \mathrm{~Hz})$ did not significantly change movement deficits [14].

These results, stress the influence of the cortico-subcortical projection on motor outputs in pre-clinical models, suggesting the idea of cortical therapeutic applications for parkinsonian 
patients [118]. This condition would imply only superficial light delivery systems, making them less invasive techniques compared to DBS methods.

Moreover, optogenetics can be combined with pharmacological treatments (L-DOPA) to achieve higher improvement [115], with limited side effects [119]. Indeed, L-DOPA induced dyskinesia (LIDs) is a crucial compliance for Parkinson's pharmacological treatments. Optogenetic stimulation of striatal cholinergic system $[113,119]$ led to a reduction of LIDs symptoms. Even in this work, different stimulation modalities imply opposite results—short pulse optical stimulation (1-5 ms) increased LIDs (the forelimb use decreased from $59.4 \pm 4 \%$ after only L-DOPA treatment to $58.3 \pm 7.5 \%$ total after short stimulation), while longer pulse optical stimulation (20 ms-1 s) significantly decreased LIDs in parkinsonian mice (the forelimb use increased up to $61.6 \pm 1.8 \%$ total compared to only L-DOPA treatment showed before) [119]. More importantly, all these results prove how frequency and pulse width are relevant to the success of optogenetic treatments [14,98,114,119]. Indeed (i) symptoms aggravation, (ii) side effects, or (iii) no effect happened when the wrong stimulation parameters were operated.

\subsection{Stroke}

One of the main goals concerning this pathology is to understand how the neuronal excitation/inhibition balance governs recovery after stroke. Thus, a selected neuron population can be put under the control of an excitatory or inhibitory opsin like in the case of Jiang et al. work. They have assessed the effects of striatal GABAergic neuronal activity on neurobehavioral outcomes after an ischemic injury (Transient Middle Cerebral Artery Occlusion (tMCAO)) using two different opsins: ChR2 and Arch (Archaerhodopsin) respectively to promote or inhibit this neural subtype. This study showed how the optical inhibition of striatal GABAergic neurons allowed an increase of microvessel density and growth factor density in the peri-infarct region. In contrast, their optogenetic activation induced an opposite action, increasing apoptosis and brain atrophy volume $[120,121]$. Moreover, He et al. results showed that the inhibition of striatal activity induced by a reduction in the GABAergic tone promoted the proliferation of neuronal stem cells (NSCs) in the subventricular zone (SVZ) and peri-infarct area of stroke mice [121]. Further validation of these results is provided by the Song et al. study - deep brain optogenetic stimulation of striatal glutamatergic neurons seems to promote the migration of SVZ neuroblasts into the peri-infarct area improving long-term functional recovery after stroke [122]. Overall these results demonstrate that optogenetics is a powerful tool in stroke recovery and promote functional improvement after brain ischemia.

Moreover, optogenetics can also be combined with other rehabilitation techniques such as NSCs transplantation that is a promising treatment to ameliorate stroke-damage tissues. Using two different opsins, ChR2 and ArchT, and optical fibre implantation Lu et al. in 2017 showed that inhibition but not excitation of striatal neuronal activity for $15 \mathrm{~min}$ daily reduced apoptosis and improved neurological recovery after NSC transplantation at the subacute phase after brain ischemia in mice [123]. These data demonstrate the influence of endogenous neuronal activity during the acute and chronic phase of the pathology, suggesting new selected targets to act on to avoid debilitating and permanent deficits.

Another important application of optogenetics as a rehabilitative tool is the treatment of cortical focal stroke. Even in this case, optogenetic approaches can bypass the regions directly involved in the damage and take advantage of the modulation of nuclei strongly connected with the damaged one, like the thalamus. This structure was demonstrated to play an important role in cortical focal stroke, as in Tennant et al. [124]. The authors tested an optogenetically rehabilitative paradigm by stimulating the cortical thalamic projection. In detail, optogenetic stimulation was delivered through a cranial window and consisted of $1 \mathrm{~h}$ of stimulation sessions for 6 weeks. Coupling this treatment with two-photon calcium imaging allowed demonstrating that the rehabilitation strategy used promoted the formation of new and stable thalamocortical synaptic buttons, enhancing the recovery of cortical circuit function and forepaw abilities. In parallel, another study tested optogenetic stimulation of the lateral cerebellar nucleus (LCN) that sends motor output to the cerebral cortex. Therefore, through 
optogenetic stimulation of the dentate-thalamo-cortical pathway, it is possible to modulate motor, premotor, somatosensory, and non-motor cortex areas (Figure 4B). The authors showed that selective short-term and long-term stimulation of excitatory neurons at contralesional LCN level, respectively for two or four weeks, promoted persistent recovery after stroke (tMCAO) [116].

Finally, modulation of intra-hemispheric connectivity fostered an increase in cerebral blood flow, neurovascular coupling response, and motor performance after 15 days of therapy $[110,125]$.

Even if neuronal processes leading rehabilitative effects still need further investigation, these preliminary results open the way to new therapeutic target and rehabilitation strategies in stroke patients $[110,126]$.

\subsection{Other Therapeutic Applications}

Optogenetics is a versatile tool, thus all the rehabilitative approaches showed before can be successfully applied in a wide range of diseases, simply by choosing a different neuronal target. In this section, we will present a few selected studies on other neurological disease models to provide a more global idea of the potential rehabilitative applications of optogenetics.

Therefore, optogenetics intervention has been evaluated for the treatment of epilepsy and epileptogenesis process. By using a closed-loop optogenetic strategy, the modulation of thalamic activity in real-time interrupted the seizures. This is a promising approach for pharmacologically and surgically intractable epilepsies [127].

Depression is another example where optogenetics is applied to improve clinical symptoms. Optogenetic stimulation of medial prefrontal cortex (mPFC), delivered through an optical fibre to mimic burst-like patterns of cortical activity (one light pulse every $3 \mathrm{~s}$ ), exerted a potent antidepressant-like effect in mice expressing strong a depressive-like phenotype [128]. Another interesting optogenetics application concerns the possibility to unravel the pharmacological mechanism of drugs. For instance, ketamine has been demonstrated to induce a rapid-acting antidepressant effect. The neuronal subtype that mediates this rapid response in the MPFC is not clear yet. It was demonstrated that optogenetic stimulation (60 min period-1 min on/1 min off, with $15 \mathrm{~ms}$ pulses at $10 \mathrm{~Hz}$ ) of Drd1 expressing pyramidal cells projection in the $\mathrm{MPFC}$ produced a rapid and long-lasting antidepressant response and that these neurons are required for ketamine response [129].

Optogenetics has been evaluated as therapeutic approach also for demyelinating diseases, such as multiple sclerosis (MS), in which immune-mediated demyelination of neuronal fibres impairs impulse conduction and causes axon degeneration in the central nervous system (CNS) associated with debilitating symptoms as muscle spasms [130]. Ortiz et al. in 2019 showed that a moderated, repeated long-term optogenetic stimulation of neocortex neurons affected by demyelination enhanced the differentiation of oligodendrocyte precursor cells into mature oligodendrocytes (Figure 4C). Consequently, only a repeated stimulation paradigm ( $3 \mathrm{~h}$ photostimulation session repeated every day from 7 to 13 days after injection, and composed of 36 light trains of $30 \mathrm{~s}$ delivered at $20 \mathrm{~Hz}$ separated by a resting period of $4.5 \mathrm{~min}$ ), allowed a remyelination of the damaged neurons and a widely functional recovery, identifying optogenetics as a therapeutic application against myelin degeneration [117].

All these results help to identify the processes involved in specific pathologies and make optogenetics a potential replacement of drug treatment in pre-clinical models, with the advantage of reducing the side effects of generic or high-invasive treatments.

\section{The Future of Optogenetics}

The success of optogenetic treatments in several animal models of neurological diseases led to an increasing interest to design potential therapeutic application in human disorders. The main problem to transfer optogenetic rehabilitation strategies from animal models to humans is related to the genetic encoding of optogenetic actuators. Gene therapies have already been performed using AAVs, such as in the case of haemophilia B that results from a defect in the gene encoding coagulation factor IX. 
Treatments mediated by an AAV vector showed long-term pathology correction without long-lasting toxicity in patients [131].

Gene therapy has been also used in a cardiovascular disease like heart failure (HF) that is characterized by a defect in sarcoplasmic reticulum function and low level of an enzyme named SERCA2. Gene transfer using recombinant AAV vectors carrying SERCA2a cDNA led to a recovery of enzyme levels in HF patients [132,133]. In these recombinant viral-based therapies, non-replicative and non-pathogenic human viruses are used. However, one persistent problem is related to the arousal of an immunological reaction against the virus, which inhibits vector uptake and shall be neutralized to maximize the efficacy of the treatment.

The in-vitro application of optogenetics in human-derived cells, provided the important evidence that this method could be applied to humans $[134,135]$. However, critical issues in optogenetic therapy remain the expression of optogenetic sensors in the human cell membrane and the current produced by individual actuators, properties that balance the possibility of improving a pathological condition with the risk of further neuronal damage [136]. Thus, to learn more about the potential barriers for human application, we cited interesting topic-focused reviews [136-139]. Nevertheless, first encouraging results in optogenetic therapies were obtained in in-vitro human neuromuscular disease and retinitis pigmentosa (PR) treatment, in which $\mathrm{ChR} 2$ and $\mathrm{NpHR}$ were combined to restore photosensitivity and interfere with disease progression [140,141], providing evidence of the potential of optogenetics also in human research fields.

Author Contributions: E.M., F.R., A.L., A.M. conceived and wrote the paper; F.S.P obtained funding support. All authors approved the paper.

Funding: This project has received funding from the H2020 EXCELLENT SCIENCE-European Research Council (ERC) under grant agreement ID n. 692943 BrainBIT". In addition, it was supported by the European Union's Horizon 2020 research and innovation program under grant agreements No. 785907 (SGA2) Human Brain Project.

Conflicts of Interest: The authors declare no conflict of interest.

\section{References}

1. Kravitz, A.V.; Kreitzer, A.C. Optogenetic manipulation of neural circuitry in vivo. Curr. Opin. Neurobiol. 2011, 21, 433-439. [CrossRef] [PubMed]

2. Carter, M.E.; de Lecea, L. Optogenetic investigation of neural circuits in vivo. Trends Mol. Med. 2011, 17, 197-206. [CrossRef] [PubMed]

3. Tye, K.M.; Deisseroth, K. Optogenetic investigation of neural circuits underlying brain disease in animal models. Nat. Rev. Neurosci. 2012, 13, 251-266. [CrossRef] [PubMed]

4. Huang, F.; Tang, B.; Jiang, H. Optogenetic investigation of neuropsychiatric diseases. Int. J. Neurosci. 2013, 123, 7-16. [CrossRef] [PubMed]

5. Hegemann, P.; Sigrist, S. Optogenetics; De gruyter: Vienna, Austria, 2013.

6. Eickelbeck, D.; Karapinar, R.; Herlitze, S.; Spoida, K. Optogenetic Approaches for Controlling Neuronal Activity and Plasticity. In Handbook of In Vivo Neural Plasticity Techniques; Elsevier: Amsterdam, The Netherlands, 2018; pp. 285-310. [CrossRef]

7. Zhang, F.; Wang, L.P.; Brauner, M.; Liewald, J.F.; Kay, K.; Watzke, N.; Wood, P.G.; Bamberg, E.; Nagel, G.; Gottschalk, A.; et al. Multimodal fast optical interrogation of neural circuitry. Nature 2007, 446, 633-639. [CrossRef] [PubMed]

8. Lin, J.Y. A user's guide to channelrhodopsin variants: Features, limitations and future developments. Exp. Physiol. 2011, 96, 19-25. [CrossRef] [PubMed]

9. Lin, J.Y. Optogenetic excitation of neurons with channelrhodopsins: Light instrumentation, expression systems, and channelrhodopsin variants. Prog. Brain Res. 2012, 196, 29-47. [CrossRef]

10. Raimondo, J.V.; Kay, L.; Ellender, T.J.; Akerman, C.J. Optogenetic silencing strategies differ in their effects on inhibitory synaptic transmission. Nat. Neurosci. 2012, 15, 1102-1104. [CrossRef]

11. Karra, D.; Dahm, R. Transfection techniques for neuronal cells. J. Neurosci. 2010, 30, 6171-6177. [CrossRef]

12. Murlidharan, G.; Samulski, R.J.; Asokan, A. Biology of adeno-associated viral vectors in the central nervous system. Front. Mol. Neurosci. 2014, 7, 76. [CrossRef] 
13. Zingg, B.; Chou, X.L.; Zhang, Z.G.; Mesik, L.; Liang, F.; Tao, H.W.; Zhang, L.I. AAV-Mediated Anterograde Transsynaptic Tagging: Mapping Corticocollicular Input-Defined Neural Pathways for Defense Behaviors. Neuron 2017, 93, 33-47. [CrossRef] [PubMed]

14. Sanders, T.H.; Jaeger, D. Optogenetic stimulation of cortico-subthalamic projections is sufficient to ameliorate bradykinesia in 6-ohda lesioned mice. Neurobiol. Dis. 2016, 95, 225-237. [CrossRef] [PubMed]

15. Zeng, H.; Madisen, L. Mouse transgenic approaches in optogenetics. Prog. Brain Res. 2012, 196, $193-213$. [CrossRef] [PubMed]

16. Harrison, T.C.; Ayling, O.G.; Murphy, T.H. Distinct cortical circuit mechanisms for complex forelimb movement and motor map topography. Neuron 2012, 74, 397-409. [CrossRef] [PubMed]

17. Hausser, M. Optogenetics: The age of light. Nat. Methods 2014, 11, 1012-1014. [CrossRef] [PubMed]

18. Steinmetz, N.A.; Buetfering, C.; Lecoq, J.; Lee, C.R.; Peters, A.J.; Jacobs, E.A.K.; Coen, P.; Ollerenshaw, D.R.; Valley, M.T.; de Vries, S.E.J.; et al. Aberrant Cortical Activity in Multiple GCaMP6-Expressing Transgenic Mouse Lines. eNeuro 2017, 4. [CrossRef] [PubMed]

19. Miyashita, T.; Shao, Y.R.; Chung, J.; Pourzia, O.; Feldman, D.E. Long-term channelrhodopsin-2 (ChR2) expression can induce abnormal axonal morphology and targeting in cerebral cortex. Front. Neural Circuits 2013, 7, 8. [CrossRef]

20. Wang, X. Cre transgenic mouse lines. Methods Mol. Biol. 2009, 561, 265-273. [CrossRef]

21. Ferenczi, E.A.; Vierock, J.; Atsuta-Tsunoda, K.; Tsunoda, S.P.; Ramakrishnan, C.; Gorini, C.; Thompson, K.; Lee, S.Y.; Berndt, A.; Perry, C.; et al. Optogenetic approaches addressing extracellular modulation of neural excitability. Sci. Rep. 2016, 6, 23947. [CrossRef]

22. Forli, A.; Vecchia, D.; Binini, N.; Succol, F.; Bovetti, S.; Moretti, C.; Nespoli, F.; Mahn, M.; Baker, C.A.; Bolton, M.M.; et al. Two-Photon Bidirectional Control and Imaging of Neuronal Excitability with High Spatial Resolution In Vivo. Cell Rep. 2018, 22, 3087-3098. [CrossRef]

23. Simonova, N.A.; Bal, N.V.; Balaban, P.M.; Volgushev, M.A.; Malyshev, A.Y. An Optogenetic Approach to Studies of the Mechanisms of Heterosynaptic Plasticity in Neocortical Neurons. Neurosci. Behav. Physiol. 2019, 49, 208-215. [CrossRef]

24. Hira, R.; Terada, S.; Kondo, M.; Matsuzaki, M. Distinct Functional Modules for Discrete and Rhythmic Forelimb Movements in the Mouse Motor Cortex. J. Neurosci. 2015, 35, 13311-13322. [CrossRef] [PubMed]

25. Smith, I.T. The ripple effect of a single neuron. Nature 2019, 567, 320-321. [CrossRef]

26. Papagiakoumou, E. Optical developments for optogenetics. Biol. Cell 2013, 105, 443-464. [CrossRef] [PubMed]

27. Oron, D.; Papagiakoumou, E.; Anselmi, F.; Emiliani, V. Two-photon optogenetics. Prog. Brain Res. 2012, 196, 119-143. [CrossRef]

28. Packer, A.M.; Roska, B.; Hausser, M. Targeting neurons and photons for optogenetics. Nat. Neurosci. 2013, 16, 805-815. [CrossRef] [PubMed]

29. Goncalves, S.B.; Ribeiro, J.F.; Silva, A.F.; Costa, R.M.; Correia, J.H. Design and manufacturing challenges of optogenetic neural interfaces: A review. J. Neural Eng. 2017, 14, 041001. [CrossRef]

30. Grossman, N.; Poher, V.; Grubb, M.S.; Kennedy, G.T.; Nikolic, K.; McGovern, B.; Berlinguer Palmini, R.; Gong, Z.; Drakakis, E.M.; Neil, M.A.; et al. Multi-site optical excitation using ChR2 and micro-LED array. J. Neural Eng. 2010, 7, 16004. [CrossRef] [PubMed]

31. Scharf, R.; Tsunematsu, T.; McAlinden, N.; Dawson, M.D.; Sakata, S.; Mathieson, K. Depth-specific optogenetic control in vivo with a scalable, high-density muLED neural probe. Sci. Rep. 2016, 6, 28381. [CrossRef] [PubMed]

32. McAlinden, N.; Gu, E.; Dawson, M.D.; Sakata, S.; Mathieson, K. Optogenetic activation of neocortical neurons in vivo with a sapphire-based micro-scale LED probe. Front. Neural Circuits 2015, 9, 25. [CrossRef] [PubMed]

33. Wu, F.; Stark, E.; Ku, P.C.; Wise, K.D.; Buzsaki, G.; Yoon, E. Monolithically Integrated muLEDs on Silicon Neural Probes for High-Resolution Optogenetic Studies in Behaving Animals. Neuron 2015, 88, 1136-1148. [CrossRef] [PubMed]

34. Silasi, G.; Boyd, J.D.; Ledue, J.; Murphy, T.H. Improved methods for chronic light-based motor mapping in mice: Automated movement tracking with accelerometers, and chronic EEG recording in a bilateral thin-skull preparation. Front. Neural Circuits 2013, 7, 123. [CrossRef] [PubMed] 
35. Vanni, M.P.; Chan, A.W.; Balbi, M.; Silasi, G.; Murphy, T.H. Mesoscale Mapping of Mouse Cortex Reveals Frequency-Dependent Cycling between Distinct Macroscale Functional Modules. J. Neurosci. 2017, 37, 7513-7533. [CrossRef] [PubMed]

36. Papagiakoumou, E.; Bègue, A.; Leshem, B.; Schwartz, O.; Stell, B.M.; Bradley, J.; Oron, D.; Emiliani, V. Functional patterned multiphoton excitation deep inside scattering tissue. Nat. Photonics 2013, 7, 274-278. [CrossRef]

37. Portugues, R.; Severi, K.E.; Wyart, C.; Ahrens, M.B. Optogenetics in a transparent animal: Circuit function in the larval zebrafish. Curr. Opin. Neurobiol. 2013, 23, 119-126. [CrossRef]

38. Jacques, S.L. Corrigendum: Optical properties of biological tissues: A review. Phys. Med. Biol. 2013, 58, 5007-5008. [CrossRef]

39. Schultz, S.R.; Copeland, C.S.; Foust, A.J.; Quicke, P.; Schuck, R. Advances in two photon scanning and scanless microscopy technologies for functional neural circuit imaging. Proc. IEEE Inst. Electr. Electron. Eng. 2017, 105, 139-157. [CrossRef]

40. Saggau, P. New methods and uses for fast optical scanning. Curr. Opin. Neurobiol. 2006, 16, 543-550. [CrossRef]

41. Packer, A.M.; Peterka, D.S.; Hirtz, J.; Prakash, R.; Deisseroth, K.; Yuste, R. Two-photon optogenetics of dendritic spines and neural circuits in 3D. Nat. Methods 2012, 9, 1202-1205. [CrossRef]

42. Papagiakoumou, E.; Anselmi, F.; Begue, A.; de Sars, V.; Gluckstad, J.; Isacoff, E.Y.; Emiliani, V. Scanless two-photon excitation of channelrhodopsin-2. Nat. Methods 2010, 7, 848-854. [CrossRef]

43. Rickgauer, J.P.; Tank, D.W. Two-photon excitation of channelrhodopsin-2 at saturation. Proc. Natl. Acad. Sci. USA 2009, 106, 15025-15030. [CrossRef] [PubMed]

44. Shemesh, O.A.; Tanese, D.; Zampini, V.; Linghu, C.; Piatkevich, K.; Ronzitti, E.; Papagiakoumou, E.; Boyden, E.S.; Emiliani, V. Temporally precise single-cell-resolution optogenetics. Nat. Neurosci. 2017, 20, 1796-1806. [CrossRef] [PubMed]

45. Ronzitti, E.; Conti, R.; Zampini, V.; Tanese, D.; Foust, A.J.; Klapoetke, N.; Boyden, E.S.; Papagiakoumou, E.; Emiliani, V. Submillisecond Optogenetic Control of Neuronal Firing with Two-Photon Holographic Photoactivation of Chronos. J. Neurosci. 2017, 37, 10679-10689. [CrossRef] [PubMed]

46. Lim, D.H.; LeDue, J.M.; Mohajerani, M.H.; Murphy, T.H. Optogenetic mapping after stroke reveals network-wide scaling of functional connections and heterogeneous recovery of the peri-infarct. J. Neurosci. 2014, 34, 16455-16466. [CrossRef] [PubMed]

47. Conti, E.; Allegra Mascaro, A.; Pavone, F. Large Scale Double-Path Illumination System with Split Field of View for the All-Optical Study of Inter-and Intra-Hemispheric Functional Connectivity on Mice. Methods Protoc. 2019, 2, 11. [CrossRef] [PubMed]

48. Guo, Z.V.; Hart, A.C.; Ramanathan, S. Optical interrogation of neural circuits in Caenorhabditis elegans. Nat. Methods 2009, 6, 891-896. [CrossRef] [PubMed]

49. Lim, D.H.; Ledue, J.; Mohajerani, M.H.; Vanni, M.P.; Murphy, T.H. Optogenetic approaches for functional mouse brain mapping. Front. Neurosci. 2013, 7, 54. [CrossRef] [PubMed]

50. Prakash, R.; Yizhar, O.; Grewe, B.; Ramakrishnan, C.; Wang, N.; Goshen, I.; Packer, A.M.; Peterka, D.S.; Yuste, R.; Schnitzer, M.J.; et al. Two-photon optogenetic toolbox for fast inhibition, excitation and bistable modulation. Nat. Methods 2012, 9, 1171-1179. [CrossRef] [PubMed]

51. Carmi, I.; De Battista, M.; Maddalena, L.; Carroll, E.C.; Kienzler, M.A.; Berlin, S. Holographic two-photon activation for synthetic optogenetics. Nat. Protoc. 2019, 14, 864-900. [CrossRef] [PubMed]

52. Nikolenko, V.; Watson, B.O.; Araya, R.; Woodruff, A.; Peterka, D.S.; Yuste, R. SLM Microscopy: Scanless Two-Photon Imaging and Photostimulation with Spatial Light Modulators. Front. Neural Circuits 2008, 2, 5. [CrossRef] [PubMed]

53. Lin, J.-Y.; Huang, R.-P.; Tsai, P.-S.; Lee, C.-H. Wide-field super-resolution optical sectioning microscopy using a single spatial light modulator. J. Opt. A Pure Appl. Opt. 2009, 11. [CrossRef]

54. Yang, W.; Carrillo-Reid, L.; Bando, Y.; Peterka, D.S.; Yuste, R. Simultaneous two-photon imaging and two-photon optogenetics of cortical circuits in three dimensions. eLife 2018, 7, e32671. [CrossRef] [PubMed]

55. Dal Maschio, M.; Donovan, J.C.; Helmbrecht, T.O.; Baier, H. Linking Neurons to Network Function and Behavior by Two-Photon Holographic Optogenetics and Volumetric Imaging. Neuron 2017, 94, 774-789. [CrossRef] [PubMed] 
56. Rickgauer, J.P.; Deisseroth, K.; Tank, D.W. Simultaneous cellular-resolution optical perturbation and imaging of place cell firing fields. Nat. Neurosci. 2014, 17, 1816-1824. [CrossRef] [PubMed]

57. Pegard, N.C.; Mardinly, A.R.; Oldenburg, I.A.; Sridharan, S.; Waller, L.; Adesnik, H. Three-dimensional scanless holographic optogenetics with temporal focusing (3D-SHOT). Nat. Commun. 2017, 8, 1228. [CrossRef] [PubMed]

58. Chen, I.W.; Ronzitti, E.; Lee, B.R.; Daigle, T.L.; Dalkara, D.; Zeng, H.; Emiliani, V.; Papagiakoumou, E. In vivo sub-millisecond two-photon optogenetics with temporally focused patterned light. J. Neurosci. 2019. [CrossRef]

59. Sileo, L.; Pisanello, M.; della Patria, A.; Emhara, M.S.; Pisanello, F.; De Vittorio, M. Optical Fiber Technologies for in-vivo Light Delivery and Optogenetics. In Proceedings of the 2015 17th International Conference on Transparent Optical Networks (ICTON), Budapest, Hungary, 5-9 July 2015. [CrossRef]

60. Nazempour, R.; Zhang, Q.; Fu, R.; Sheng, X. Biocompatible and Implantable Optical Fibers and Waveguides for Biomedicine. Materials 2018, 11, 1283. [CrossRef]

61. Yoon, H.H.; Park, J.H.; Kim, Y.H.; Min, J.; Hwang, E.; Lee, C.J.; Suh, J.K.; Hwang, O.; Jeon, S.R. Optogenetic inactivation of the subthalamic nucleus improves forelimb akinesia in a rat model of Parkinson disease. Neurosurgery 2014, 74, 533-540. [CrossRef]

62. Pisanello, M.; Pisano, F.; Sileo, L.; Maglie, E.; Bellistri, E.; Spagnolo, B.; Mandelbaum, G.; Sabatini, B.L.; De Vittorio, M.; Pisanello, F. Tailoring light delivery for optogenetics by modal demultiplexing in tapered optical fibers. Sci. Rep. 2018, 8, 4467. [CrossRef]

63. Pisanello, F.; Mandelbaum, G.; Pisanello, M.; Oldenburg, I.A.; Sileo, L.; Markowitz, J.E.; Peterson, R.E.; Della Patria, A.; Haynes, T.M.; Emara, M.S.; et al. Dynamic illumination of spatially restricted or large brain volumes via a single tapered optical fiber. Nat. Neurosci. 2017, 20, 1180-1188. [CrossRef]

64. Arlow, R.L.; Foutz, T.J.; McIntyre, C.C. Theoretical principles underlying optical stimulation of myelinated axons expressing channelrhodopsin-2. Neuroscience 2013, 248, 541-551. [CrossRef] [PubMed]

65. Montgomery, K.L.; Yeh, A.J.; Ho, J.S.; Tsao, V.; Mohan Iyer, S.; Grosenick, L.; Ferenczi, E.A.; Tanabe, Y.; Deisseroth, K.; Delp, S.L.; et al. Wirelessly powered, fully internal optogenetics for brain, spinal and peripheral circuits in mice. Nat. Methods 2015, 12, 969-974. [CrossRef] [PubMed]

66. McCall, J.G.; Kim, T.I.; Shin, G.; Huang, X.; Jung, Y.H.; Al-Hasani, R.; Omenetto, F.G.; Bruchas, M.R.; Rogers, J.A. Fabrication and application of flexible, multimodal light-emitting devices for wireless optogenetics. Nat. Protoc. 2013, 8, 2413-2428. [CrossRef] [PubMed]

67. Kale, R.P.; Kouzani, A.Z.; Berk, M.; Walder, K.; Berk, J.; Tye, S.J. Wireless Optogenetics: An Exploration of Portable Microdevices for Small Animal Photostimulation. Procedia Technol. 2015, 20, 225-230. [CrossRef]

68. Kwon, K.Y.; Lee, H.M.; Ghovanloo, M.; Weber, A.; Li, W. Design, fabrication, and packaging of an integrated, wirelessly-powered optrode array for optogenetics application. Front. Syst. Neurosci. 2015, 9, 69. [CrossRef] [PubMed]

69. Zhao, Y.; Liu, C.; Liu, Z.; Luo, W.; Li, L.; Cai, X.; Liang, D.; Su, Y.; Ding, H.; Wang, Q.; et al. Wirelessly Operated, Implantable Optoelectronic Probes for Optogenetics in Freely Moving Animals. IEEE Trans. Electron Devices 2019, 66, 785-792. [CrossRef]

70. Emara, M.S.; Pisanello, M.; Sileo, L.; De Vittorio, M.; Pisanello, F. A Wireless Head-mountable Device with Tapered Optical Fiber-coupled Laser Diode for Light Delivery in Deep Brain Regions. IEEE Trans. Biomed. Eng. 2018, 66, 1996-2009. [CrossRef]

71. Owen, S.F.; Liu, M.H.; Kreitzer, A.C. Thermal constraints on in vivo optogenetic manipulations. Nat. Neurosci. 2019, 22, 1061-1065. [CrossRef]

72. Gysbrechts, B.; Wang, L.; Trong, N.N.; Cabral, H.; Navratilova, Z.; Battaglia, F.; Saeys, W.; Bartic, C. Light distribution and thermal effects in the rat brain under optogenetic stimulation. J. Biophotonics 2016, 9, 576-585. [CrossRef]

73. Ait Ouares, K.; Beurrier, C.; Canepari, M.; Laverne, G.; Kuczewski, N. Opto nongenetics inhibition of neuronal firing. Eur. J. Neurosci. 2019, 49, 6-26. [CrossRef]

74. Jazayeri, M.; Lindbloom-Brown, Z.; Horwitz, G.D. Saccadic eye movements evoked by optogenetic activation of primate V1. Nat. Neurosci. 2012, 15, 1368-1370. [CrossRef] [PubMed]

75. Soma, S.; Yoshida, J.; Kato, S.; Takahashi, Y.; Nonomura, S.; Sugimura, Y.K.; Rios, A.; Kawabata, M.; Kobayashi, K.; Kato, F.; et al. Ipsilateral-Dominant Control of Limb Movements in Rodent Posterior Parietal Cortex. J. Neurosci. 2019, 39, 485-502. [CrossRef] [PubMed] 
76. Makino, H.; Ren, C.; Liu, H.; Kim, A.N.; Kondapaneni, N.; Liu, X.; Kuzum, D.; Komiyama, T. Transformation of Cortex-wide Emergent Properties during Motor Learning. Neuron 2017, 94, 880-890.e888. [CrossRef] [PubMed]

77. Montagni, E.; Resta, F.; Conti, E.; Scaglione, A.; Pasquini, M.; Micera, S.; Mascaro, A.L.A.; Pavone, F.S. Wide-field imaging of cortical neuronal activity with red-shifted functional indicators during motor task execution. J. Phys. D Appl. Phys. 2019, 52. [CrossRef]

78. Choi, J.H.; Koch, K.P.; Poppendieck, W.; Lee, M.; Shin, H.S. High resolution electroencephalography in freely moving mice. J. Neurophysiol. 2010, 104, 1825-1834. [CrossRef] [PubMed]

79. Ferezou, I.; Haiss, F.; Gentet, L.J.; Aronoff, R.; Weber, B.; Petersen, C.C. Spatiotemporal dynamics of cortical sensorimotor integration in behaving mice. Neuron 2007, 56, 907-923. [CrossRef]

80. Kravitz, A.V.; Freeze, B.S.; Parker, P.R.; Kay, K.; Thwin, M.T.; Deisseroth, K.; Kreitzer, A.C. Regulation of parkinsonian motor behaviours by optogenetic control of basal ganglia circuitry. Nature 2010, 466, 622-626. [CrossRef]

81. Akerboom, J.; Carreras Calderon, N.; Tian, L.; Wabnig, S.; Prigge, M.; Tolo, J.; Gordus, A.; Orger, M.B.; Severi, K.E.; Macklin, J.J.; et al. Genetically encoded calcium indicators for multi-color neural activity imaging and combination with optogenetics. Front. Mol. Neurosci. 2013, 6, 2. [CrossRef]

82. Miesenböck, G. The Optogenetic Catechism. Science 2009, 326, 395-399. [CrossRef]

83. Lanciego, J.L.; Luquin, N.; Obeso, J.A. Functional neuroanatomy of the basal ganglia. Cold Spring Harb. Perspect. Med. 2012, 2, a009621. [CrossRef]

84. Britt, J.P.; McDevitt, R.A.; Bonci, A. Use of channelrhodopsin for activation of CNS neurons. Curr. Protoc. Neurosci. 2012. [CrossRef]

85. Freeze, B.S.; Kravitz, A.V.; Hammack, N.; Berke, J.D.; Kreitzer, A.C. Control of basal ganglia output by direct and indirect pathway projection neurons. J. Neurosci. 2013, 33, 18531-18539. [CrossRef] [PubMed]

86. Howe, M.W.; Dombeck, D.A. Rapid signalling in distinct dopaminergic axons during locomotion and reward. Nature 2016, 535, 505-510. [CrossRef] [PubMed]

87. Warden, M.R.; Selimbeyoglu, A.; Mirzabekov, J.J.; Lo, M.; Thompson, K.R.; Kim, S.Y.; Adhikari, A.; Tye, K.M.; Frank, L.M.; Deisseroth, K. A prefrontal cortex-brainstem neuronal projection that controls response to behavioural challenge. Nature 2012, 492, 428-432. [CrossRef] [PubMed]

88. Geddes, C.E.; Li, H.; Jin, X. Optogenetic Editing Reveals the Hierarchical Organization of Learned Action Sequences. Cell 2018, 174, 32-43. [CrossRef] [PubMed]

89. Wang, X.; Qiao, Y.; Dai, Z.; Sui, N.; Shen, F.; Zhang, J.; Liang, J. Medium spiny neurons of the anterior dorsomedial striatum mediate reversal learning in a cell-type-dependent manner. Brain Struct. Funct. 2018, 224, 419-434. [CrossRef] [PubMed]

90. Knopfel, T. Genetically encoded optical indicators for the analysis of neuronal circuits. Nat. Rev. Neurosci. 2012, 13, 687-700. [CrossRef]

91. Emiliani, V.; Cohen, A.E.; Deisseroth, K.; Hausser, M. All-Optical Interrogation of Neural Circuits. J. Neurosci. 2015, 35, 13917-13926. [CrossRef]

92. Bando, Y.; Sakamoto, M.; Kim, S.; Ayzenshtat, I.; Yuste, R. Comparative Evaluation of Genetically Encoded Voltage Indicators. Cell Rep. 2019, 26, 802-813. [CrossRef]

93. Tian, L.; Akerboom, J.; Schreiter, E.R.; Looger, L.L. Neural activity imaging with genetically encoded calcium indicators. Prog. Brain Res. 2012, 196, 79-94. [CrossRef]

94. Kim, C.K.; Adhikari, A.; Deisseroth, K. Integration of optogenetics with complementary methodologies in systems neuroscience. Nat. Rev. Neurosci. 2017, 18, 222-235. [CrossRef] [PubMed]

95. Chemla, S.; Chavane, F. Voltage-sensitive dye imaging: Technique review and models. J. Physiol. Paris 2010, 104, 40-50. [CrossRef] [PubMed]

96. Labat-gest, V.; Tomasi, S. Photothrombotic ischemia: A minimally invasive and reproducible photochemical cortical lesion model for mouse stroke studies. J. Vis. Exp. 2013. [CrossRef] [PubMed]

97. Xie, Y.; Chen, S.; Anenberg, E.; Murphy, T.H. Resistance of optogenetically evoked motor function to global ischemia and reperfusion in mouse in vivo. J. Cereb. Blood Flow Metab. 2013, 33, 1148-1152. [CrossRef] [PubMed]

98. Kim, J.; Kim, Y.; Nakajima, R.; Shin, A.; Jeong, M.; Park, A.H.; Jeong, Y.; Jo, S.; Yang, S.; Park, H.; et al. Inhibitory Basal Ganglia Inputs Induce Excitatory Motor Signals in the Thalamus. Neuron 2017, 95, 1181-1196. [CrossRef] [PubMed] 
99. Burguiere, E.; Monteiro, P.; Feng, G.; Graybiel, A.M. Optogenetic stimulation of lateral orbitofronto-striatal pathway suppresses compulsive behaviors. Science 2013, 340, 1243-1246. [CrossRef] [PubMed]

100. Cela, E.; McFarlan, A.R.; Chung, A.J.; Wang, T.; Chierzi, S.; Murai, K.K.; Sjöström, P.J. An Optogenetic Kindling Model of Neocortical Epilepsy. Sci. Rep. 2019, 9. [CrossRef]

101. Chaudhury, D.; Walsh, J.J.; Friedman, A.K.; Juarez, B.; Ku, S.M.; Koo, J.W.; Ferguson, D.; Tsai, H.C.; Pomeranz, L.; Christoffel, D.J.; et al. Rapid regulation of depression-related behaviours by control of midbrain dopamine neurons. Nature 2013, 493, 532-536. [CrossRef]

102. Lomarev, M.P.; Kanchana, S.; Bara-Jimenez, W.; Iyer, M.; Wassermann, E.M.; Hallett, M. Placebo-controlled study of rTMS for the treatment of Parkinson's disease. Mov. Disord. 2006, 21, 325-331. [CrossRef]

103. Kubis, N. Non-Invasive Brain Stimulation to Enhance Post-Stroke Recovery. Front. Neural Circuits 2016, 10, 56. [CrossRef]

104. Pallanti, S.; Bernardi, S. Neurobiology of repeated transcranial magnetic stimulation in the treatment of anxiety: A critical review. Int. Clin. Psychopharmacol. 2009, 24, 163-173. [CrossRef] [PubMed]

105. Elder, G.J.; Taylor, J.P. Transcranial magnetic stimulation and transcranial direct current stimulation: Treatments for cognitive and neuropsychiatric symptoms in the neurodegenerative dementias? Alzheimers Res. Ther. 2014, 6. [CrossRef] [PubMed]

106. Stilling, J.M.; Monchi, O.; Amoozegar, F.; Debert, C.T. Transcranial Magnetic and Direct Current Stimulation (TMS/tDCS) for the Treatment of Headache: A Systematic Review. Headache 2019, 59, 339-357. [CrossRef] [PubMed]

107. Guggisberg, A.G.; Koch, P.J.; Hummel, F.C.; Buetefisch, C. Brain networks and their relevance for stroke rehabilitation. Clin. Neurophysiol. 2019, 130, 1098-1124. [CrossRef] [PubMed]

108. Fregni, F.; Boggio, P.S.; Santos, M.C.; Lima, M.; Vieira, A.L.; Rigonatti, S.P.; Silva, M.T.; Barbosa, E.R.; Nitsche, M.A.; Pascual-Leone, A. Noninvasive cortical stimulation with transcranial direct current stimulation in Parkinson's disease. Mov. Disord. 2006, 21, 1693-1702. [CrossRef]

109. Naro, A.; Milardi, D.; Russo, M.; Terranova, C.; Rizzo, V.; Cacciola, A.; Marino, S.; Calabro, R.S.; Quartarone, A. Non-invasive Brain Stimulation, a Tool to Revert Maladaptive Plasticity in Neuropathic Pain. Front. Hum. Neurosci. 2016, 10, 376. [CrossRef]

110. Cheng, M.Y.; Aswendt, M.; Steinberg, G.K. Optogenetic Approaches to Target Specific Neural Circuits in Post-stroke Recovery. Neurotherapeutics 2016, 13, 325-340. [CrossRef]

111. Benabid, A.L.; Chabardes, S.; Mitrofanis, J.; Pollak, P. Deep brain stimulation of the subthalamic nucleus for the treatment of Parkinson's disease. Lancet Neurol 2009, 8, 67-81. [CrossRef]

112. Wichmann, T.; DeLong, M.R.; Guridi, J.; Obeso, J.A. Milestones in research on the pathophysiology of Parkinson's disease. Mov. Disord. 2011, 26, 1032-1041. [CrossRef]

113. Ztaou, S.; Amalric, M. Contribution of cholinergic interneurons to striatal pathophysiology in Parkinson's disease. Neurochem. Int. 2019, 126, 1-10. [CrossRef]

114. Seeger-Armbruster, S.; Bosch-Bouju, C.; Little, S.T.; Smither, R.A.; Hughes, S.M.; Hyland, B.I.; Parr-Brownlie, L.C. Patterned, but not tonic, optogenetic stimulation in motor thalamus improves reaching in acute drug-induced Parkinsonian rats. J. Neurosci. 2015, 35, 1211-1216. [CrossRef] [PubMed]

115. Viana Magno, L.A.; Tenza-Ferrer, H.; Collodetti, M.; Felipe Guimaraes Aguiar, M.; Paula Carneiro Rodrigues, A.; Souza da Silva, R.; do Prado Silva, J.; Ferreira Nicolau, N.; Valadao Freitas Rosa, D.; Birbrair, A.; et al. Optogenetic stimulation of the M2 cortex reverts motor dysfunction in a mouse model of Parkinson's Disease. J. Neurosci. 2019. [CrossRef]

116. Shah, A.M.; Ishizaka, S.; Cheng, M.Y.; Wang, E.H.; Bautista, A.R.; Levy, S.; Smerin, D.; Sun, G.; Steinberg, G.K. Optogenetic neuronal stimulation of the lateral cerebellar nucleus promotes persistent functional recovery after stroke. Sci. Rep. 2017, 7, 46612. [CrossRef] [PubMed]

117. Ortiz, F.C.; Habermacher, C.; Graciarena, M.; Houry, P.Y.; Nishiyama, A.; Nait-Oumesmar, B.; Angulo, M.C. Neuronal activity in vivo enhances functional myelin repair. JCI Insight 2019, 5, 123434. [CrossRef] [PubMed]

118. Lefaucheur, J.P. Motor cortex dysfunction revealed by cortical excitability studies in Parkinson's disease: Influence of antiparkinsonian treatment and cortical stimulation. Clin. Neurophysiol. 2005, 116, 244-253. [CrossRef] [PubMed]

119. Bordia, T.; Perez, X.A.; Heiss, J.; Zhang, D.; Quik, M. Optogenetic activation of striatal cholinergic interneurons regulates L-dopa-induced dyskinesias. Neurobiol. Dis. 2016, 91, 47-58. [CrossRef] 
120. Jiang, L.; Li, W.; Mamtilahun, M.; Song, Y.; Ma, Y.; Qu, M.; Lu, Y.; He, X.; Zheng, J.; Fu, Z.; et al. Optogenetic Inhibition of Striatal GABAergic Neuronal Activity Improves Outcomes After Ischemic Brain Injury. Stroke 2017, 48, 3375-3383. [CrossRef]

121. He, X.; Lu, Y.; Lin, X.; Jiang, L.; Tang, Y.; Tang, G.; Chen, X.; Zhang, Z.; Wang, Y.; Yang, G.Y. Optical inhibition of striatal neurons promotes focal neurogenesis and neurobehavioral recovery in mice after middle cerebral artery occlusion. J. Cereb. Blood Flow Metab. 2017, 37, 837-847. [CrossRef]

122. Song, M.; Yu, S.P.; Mohamad, O.; Cao, W.; Wei, Z.Z.; Gu, X.; Jiang, M.Q.; Wei, L. Optogenetic stimulation of glutamatergic neuronal activity in the striatum enhances neurogenesis in the subventricular zone of normal and stroke mice. Neurobiol. Dis. 2017, 98, 9-24. [CrossRef]

123. Lu, Y.; Jiang, L.; Li, W.; Qu, M.; Song, Y.; He, X.; Zhang, Z.; Yang, G.Y.; Wang, Y. Optogenetic Inhibition of Striatal Neuronal Activity Improves the Survival of Transplanted Neural Stem Cells and Neurological Outcomes after Ischemic Stroke in Mice. Stem Cells Int. 2017, 2017, 4364302. [CrossRef]

124. Tennant, K.A.; Taylor, S.L.; White, E.R.; Brown, C.E. Optogenetic rewiring of thalamocortical circuits to restore function in the stroke injured brain. Nat. Commun. 2017, 8, 15879. [CrossRef] [PubMed]

125. Cheng, M.Y.; Wang, E.H.; Woodson, W.J.; Wang, S.; Sun, G.; Lee, A.G.; Arac, A.; Fenno, L.E.; Deisseroth, K.; Steinberg, G.K. Optogenetic neuronal stimulation promotes functional recovery after stroke. Proc. Natl. Acad. Sci. USA 2014, 111, 12913-12918. [CrossRef] [PubMed]

126. Lu, C.; Wu, X.; Ma, H.; Wang, Q.; Wang, Y.; Luo, Y.; Li, C.; Xu, H. Optogenetic Stimulation Enhanced Neuronal Plasticities in Motor Recovery after Ischemic Stroke. Neural Plast. 2019, 2019, 5271573. [CrossRef] [PubMed]

127. Paz, J.T.; Davidson, T.J.; Frechette, E.S.; Delord, B.; Parada, I.; Peng, K.; Deisseroth, K.; Huguenard, J.R. Closed-loop optogenetic control of thalamus as a tool for interrupting seizures after cortical injury. Nat. Neurosci. 2013, 16, 64-70. [CrossRef] [PubMed]

128. Covington, H.E., 3rd; Lobo, M.K.; Maze, I.; Vialou, V.; Hyman, J.M.; Zaman, S.; LaPlant, Q.; Mouzon, E.; Ghose, S.; Tamminga, C.A.; et al. Antidepressant effect of optogenetic stimulation of the medial prefrontal cortex. J. Neurosci. 2010, 30, 16082-16090. [CrossRef] [PubMed]

129. Hare, B.D.; Shinohara, R.; Liu, R.J.; Pothula, S.; DiLeone, R.J.; Duman, R.S. Optogenetic stimulation of medial prefrontal cortex Drd1 neurons produces rapid and long-lasting antidepressant effects. Nat. Commun. 2019, 10, 223. [CrossRef] [PubMed]

130. Sospedra, M.; Martin, R. Immunology of multiple sclerosis. Annu. Rev. Immunol. 2005, 23, 683-747. [CrossRef] [PubMed]

131. Nathwani, A.C.; Tuddenham, E.G.; Rangarajan, S.; Rosales, C.; McIntosh, J.; Linch, D.C.; Chowdary, P.; Riddell, A.; Pie, A.J.; Harrington, C.; et al. Adenovirus-Associated Virus Vector-Mediated Gene Transfer in Hemophilia B. N. Engl. J. Med. 2011, 365, 2357-2365. [CrossRef] [PubMed]

132. Jaski, B.E.; Jessup, M.L.; Mancini, D.M.; Cappola, T.P.; Pauly, D.F.; Greenberg, B.; Borow, K.; Dittrich, H.; Zsebo, K.M.; Hajjar, R.J.; et al. Calcium upregulation by percutaneous administration of gene therapy in cardiac disease (CUPID Trial), a first-in-human phase 1/2 clinical trial. J. Card. Fail. 2009, 15, 171-181. [CrossRef] [PubMed]

133. Jessup, M.; Greenberg, B.; Mancini, D.; Cappola, T.; Pauly, D.F.; Jaski, B.; Yaroshinsky, A.; Zsebo, K.M.; Dittrich, H.; Hajjar, R.J.; et al. Calcium Upregulation by Percutaneous Administration of Gene Therapy in Cardiac Disease (CUPID): A phase 2 trial of intracoronary gene therapy of sarcoplasmic reticulum $\mathrm{Ca}^{2+}$-ATPase in patients with advanced heart failure. Circulation 2011, 124, 304-313. [CrossRef]

134. Schmieder, F.; Klapper, S.; Koukourakis, N.; Busskamp, V.; Czarske, J. Optogenetic Stimulation of Human Neural Networks Using Fast Ferroelectric Spatial Light Modulator-Based Holographic Illumination. Appl. Sci. 2018, 8, 1180. [CrossRef]

135. Andersson, M.; Avaliani, N.; Svensson, A.; Wickham, J.; Pinborg, L.H.; Jespersen, B.; Christiansen, S.H.; Bengzon, J.; Woldbye, D.P.; Kokaia, M. Optogenetic control of human neurons in organotypic brain cultures. Sci. Rep. 2016, 6, 24818. [CrossRef] [PubMed]

136. Williams, J.C.; Denison, T. From Optogenetic Technologies to Neuromodulation Therapies. Sci. Transl. Med. 2013, 5, 177ps6. [CrossRef] [PubMed]

137. Boyden, E.S. Optogenetics and the future of neuroscience. Nat. Neurosci. 2015, 18, 1200-1201. [CrossRef] [PubMed]

138. Deisseroth, K. Optogenetics. Nat. Methods 2011, 8, 26-29. [CrossRef] [PubMed] 
139. Chow, B.Y.; Boyden, E.S. Optogenetics and Translational Medicine. Sci. Transl. Med. 2013, 5, $177-181$. [CrossRef] [PubMed]

140. Busskamp, V.; Picaud, S.; Sahel, J.A.; Roska, B. Optogenetic therapy for retinitis pigmentosa. Gene Ther. 2012, 19, 169-175. [CrossRef]

141. Steinberg, E.E.; Keiflin, R.; Boivin, J.R.; Witten, I.B.; Deisseroth, K.; Janak, P.H. A causal link between prediction errors, dopamine neurons and learning. Nat. Neurosci. 2013, 16, 966-973. [CrossRef]

(c) 